\title{
Alelopatia de duas espécies de braquiária em sementes de três espécies de estilosantes
}

\author{
Allelopathy of two brachiaria species in seeds of three species of stylosanthes \\ Adriana Paula D'Agostini Contreiras Rodrigues ${ }^{I}$ Valdemir Antônio Laura ${ }^{\text {II }}$ Silvia Rahe Pereira ${ }^{\text {III }}$ \\ Caroline Deiss ${ }^{\mathrm{IV}}$
}

\section{RESUMO}

A alelopatia é muito comum em gramíneas como a Brachiaria brizantha e B. decumbens, podendo representar um problema em pastagens consorciadas com Stylosanthes, já que, nessa situação, a perpetuação da leguminosa depende da ressemeadura natural. Apesar da grande quantidade de sementes de estilosantes produzidas anualmente, nessas pastagens consorciadas, observa-se, em campo, pequena quantidade de plantas jovens, o que pode ser atribuído a um possível efeito alelopático da gramínea. Considerando a importância da alelopatia no consórcio de braquiárias com estilosantes, testou-se o potencial alelopático de extratos de Brachiaria brizantha e B. decumbens na germinação de sementes de três espécies de estilosantes. Verificou-se que há efeito alelopático negativo de B. brizantha e B. decumbens na germinação de sementes de Stylosanthes guianensis e somente de B. decumbens na germinação de S. capitata; há efeito alelopático positivo de $\boldsymbol{B}$. brizantha nas sementes de $\boldsymbol{S}$. macrocephala; não há efeito alelopático de B. brizantha na germinação de sementes de $\boldsymbol{S}$. capitata e nem de B. decumbens em S. macrocephala.

Palavras-chave: Brachiaria brizantha, Brachiaria decumbens, Stylosanthes, forrageiras, gramíneas.

\section{ABSTRACT}

The allelopathy is very common in grasses such as Brachiaria brizantha and Brachiaria decumbens, could represent a problem in pastures consortium with Stylosantes since, in this situation, the perpetuation of the legume dependent natural reseed. In spite of the great amount of estilosantes seed produced annually in those pastures consortium, it is observed in field, small amount of young plants, which can be attributed to a possible allelopathic effect of the grass. Considering the importance of allelopathy in the consortium of Brachiaria with estilosantes, we tested the allelopathic potential of extracts of $\boldsymbol{B}$. brizantha and $\boldsymbol{B}$. decumbens on seed germination of three estilosantes species. It was found that there allelopathic negative effect of $\boldsymbol{B}$. brizantha and B. decumbens on seed germination of Stylosanthes guianensis and only of $\boldsymbol{B}$. decumbens in seed S. capitata; there allelopathic positive effect of $\boldsymbol{B}$. brizantha on germination of $\boldsymbol{S}$. macrocephala; there is no allelopathic effect of $\boldsymbol{B}$. brizantha on seed germination of $\boldsymbol{S}$. capitata neither of B. decumbens in S. macrocephala.

Key words: Brachiaria brizantha, Brachiaria decumbens, Stylosanthes, fodder, grass.

\section{INTRODUÇÃO}

O Brasil possui, atualmente, uma área superior a 170 milhões de hectares ocupada por pastagens para a produção animal, o que representa, aproximadamente, o dobro da área cultivada para a produção de grãos (SILVA \& SBRISSA, 2000). Porém, segundo os autores, apesar de todo esse potencial produtivo, os resultados obtidos nos sistemas de produção em pastagens no Brasil são inferiores aos níveis passíveis de serem obtidos, tanto do ponto de vista biológico como do ponto de vista operacional.

IPrograma de Pós-graduação em Produção e Gestão Agroindustrial, Universidade Anhanguera (UNIDERP), 79037-280, Campo Grande, MS, Brasil. E-mail: adricontreiras@hotmail.com. Autor para correspondência.

"Embrapa Gado de Corte, Campo Grande, MS, Brasil.

IIIPrograma de Pós-graduação em Ecologia e Recursos Naturais, Universidade Federal de São Carlos (UFSCAR), São Carlos, SP, Brasil.

${ }^{\mathrm{IV}}$ Curso de Agronomia, UNIDERP, Campo Grande, MS, Brasil. 
Um dos pontos críticos para a produção animal, em grande parte das regiões tropicais, consiste na variação de qualidade da forragem ao longo do ano, com grande concentração da produção no período das chuvas e pequena oferta ou grande oferta de forragem, porém, de baixa qualidade na estação seca (SILVA \& SALIBA, 2007; CARVALHO\&PIRES, 2008). Aaplicação de fontes de nitrogênio na pastagem supera, em parte, os problemas quantitativos na produtividade das pastagens (CARVALHO \& PIRES, 2008) e esse elemento pode ser introduzido ao sistema por duas vias: a introdução de leguminosas forrageiras consorciadas à pastagem e/ou com a aplicação de nitrogênio mineral (SILVA \& SALIBA, 2007).

Diversos são os benefícios do consórcio entre leguminosas e a pastagem. As leguminosas aumentam o aporte de nutrientes na pastagem, aumentam a oferta de forragem em algumas épocas do ano, melhoram a qualidade nutricional da pastagem aumentando a produtividade animal, reduzem a variação anual de oferta de forragem, participam na recuperação de áreas degradadas e ainda reduzem a pressão ambiental pela utilização de fertilizantes químicos (CARVALHO \& PIRES, 2008). No entanto, podem ocorrer interações negativas entre as espécies consorciadas. Por exemplo, diversos trabalhos relatam que gramíneas forrageiras do gênero Brachiaria possuem atividade alelopática em suas sementes e partes aéreas, e inibem, muitas vezes, a germinação de sementes e o desenvolvimento de plantas de diferentes espécies (SOUZA FILHO et al., 1997; MACIEL et al., 2003; SOUZA FILHO et al., 2005).

A alelopatia é definida como qualquer efeito direto ou indireto, benéfico ou prejudicial, de uma planta ou de microorganismos sobre outra planta, mediante produção de compostos químicos (aleloquímicos) que são liberados no ambiente (RICE, 1984). Esse fenômeno ocorre em comunidades naturais de plantas (GRESSEL \& HOLM, 1964) e pode, também, interferir no crescimento das culturas agrícolas, alterando a densidade populacional e o desenvolvimento das plantas (SOUZA et al., 2006).

Os aleloquímicos, pertencentes a diversos grupos como terpenóides, esteróides, alcalóides, taninos, fenóis, cumarinas e flavanoides, são encontrados e distribuídos em concentrações variadas nas diferentes partes da planta e durante o seu ciclo de vida. Quando essas substâncias são liberadas em quantidades suficientes, podem causar efeitos na germinação de sementes, no crescimento e/ou no desenvolvimento de plantas já estabelecidas (CARVALHO, 1993), uma vez que interferem na divisão celular, na permeabilidade das membranas, na ativação de enzimas e na produção de hormônios pela planta (GORLA\& PEREZ, 1997).

Nesse contexto, a identificação de forrageiras alelopáticas e o conhecimento dos mecanismos pelos quais elas exercem seus efeitos no ambiente, reveste-se de grande importância, por propiciar um manejo mais adequado dessas plantas com vistas a aumentar a produtividade e a persistência das pastagens (REZENDE et al., 2003), especialmente no caso de pastagens consorciadas, quando devem permanecer em equilíbrio duas ou mais espécies forrageiras.

O objetivo no presente trabalho foi avaliar o potencial alelopático de extratos de Brachiaria brizantha e B. decumbens na germinação de sementes de três espécies de estilosantes.

\section{MATERIAL E MÉTODOS}

Foram realizados dois experimentos: o experimento I, com extratos de Brachiaria brizantha, cultivar 'Marandu', e o experimento II, com extratos de B. decumbens, cultivar 'Basilisk'. Avaliou-se o potencial alelopático desses extratos individualmente na germinação e no vigor de sementes de três espécies de estilosantes: Stylosanthes guianensis, $S$. macrocephala e $S$. capitata.

Para a produção dos extratos, foram utilizados $60 \mathrm{~g}$ de folhas de plantas adultas, em estágio vegetativo, das duas espécies de Brachiaria, individualmente triturados em um liquidificador com $300 \mathrm{~mL}$ de água. Em seguida, o extrato foi diluído em cinco concentrações (tratamentos): 5, 10, 15 e 20\% p/ v; na testemunha, utilizou-se apenas água destilada.

Foram utilizadas quatro repetições de 100 sementes cada para cada espécie de Stylosanthes. As sementes foram acondicionadas sobre uma folha de papel germitest umedecido com $5 \mathrm{~mL}$ de extrato, em gerbox, colocados em germinador do tipo BOD na temperatura alternada de $25-30^{\circ} \mathrm{C}$, sob fotoperíodo de 12 horas (BRASIL, 2009).

Foram realizadas contagens diárias durante 10 dias e consideradas germinadas as sementes que apresentaram mais de $2,0 \mathrm{~mm}$ de protrusão da raiz primária. As variáveis analisadas foram: primeira contagem (aos quatro dias) e última contagem do teste de germinação; índice de velocidade de germinação (IVG) e velocidade de germinação (VG) em dias. Os dados obtidos foram submetidos à análise de variância e regressão polinomial, separadamente, para cada uma das espécies de estilosantes. 


\section{RESULTADOS E DISCUSSÃO}

\section{Experimento I - Brachiaria brizantha}

Houve efeito significativo linear negativo do extrato de $\boldsymbol{B}$. brizantha na primeira contagem, na germinação total e no IVG de sementes de $\boldsymbol{S}$. guianensis (Figura 1). O aumento da concentração do extrato de B. brizantha não influenciou na variável velocidade de germinação (VG) da espécie $\boldsymbol{S}$. guianensis. Houve efeito significativo linear positivo do extrato de $\boldsymbol{B}$. brizantha na germinação final de sementes de $\mathbf{S}$. macrocephala. Pode-se ainda verificar que o efeito das concentrações dos extratos na VG foi quadrático, atrasando a germinação entre as concentrações de 5\% e $15 \%$, com efeito máximo na concentração de $12,8 \%$ (Figura 2). Não se observou efeito alelopático dos extratos de B. brizantha na primeira contagem do teste de germinação e no IVG de $\boldsymbol{S}$. macrocephala. Não foi verificado efeito alelopático dos extratos de $\boldsymbol{B}$. brizantha em sementes de S. capitata.

\section{Experimento II - Brachiaria decumbens}

Houve efeito significativo linear negativo dos extratos de $\boldsymbol{B}$. decumbens apenas no IVG de sementes de $\mathbf{S}$. guianensis (Figura 3), sendo que as demais variáveis (PC, CF e VG) não foram influenciadas por B. decumbens. Os extratos de B. decumbens não apresentaram efeito alelopático em sementes de $\boldsymbol{S}$. macrocephala. Houve efeito significativo linear negativo do extrato de $\boldsymbol{B}$. decumbens na primeira contagem, na germinação e no IVG de sementes de $\boldsymbol{S}$. capitata (Figura 4). Essa foi a espécie de estilosantes mais afetada pelos extratos de B. decumbens.

A escolha de espécies para o consórcio em pastagens deve levar em consideração as possíveis interações, positivas ou negativas, entre as espécies envolvidas. A germinação de sementes das espécies de estilosantes testadas neste estudo respondeu diferencialmente ao aumento de concentração dos extratos das duas espécies de braquiárias, informação esta importante para o estabelecimento dos consórcios.

A espécie $S$. macrocephala apresenta potencial para o consórcio tanto com B. brizantha como $\boldsymbol{B}$. decumbens, uma vez que o aumento da concentração dos extratos de ambas as espécies afetou positivamente na germinação da leguminosa ou não a alterou. Da mesma forma, $S$. capitata apresenta potencial para o consórcio com $\boldsymbol{B}$. brizantha, já que esta não afeta a germinação da leguminosa. Por outro lado, este estudo mostrou que os consórcios entre $\mathbf{S}$. guianensis e B. brizantha e $\boldsymbol{S}$. capitata e B. decumbens podem afetar negativamente na germinação de sementes das leguminosas, não representando, assim, uma boa opção para a formação e manutenção de pastagens. Porém, como os efeitos alelopáticos podem ocorrer tanto na germinação de sementes, como no crescimento e/ou no desenvolvimento de plantas já estabelecidas, estudos que acompanhem as etapas posteriores da germinação devem ser conduzidos para ratificar os resultados obtidos neste experimento.

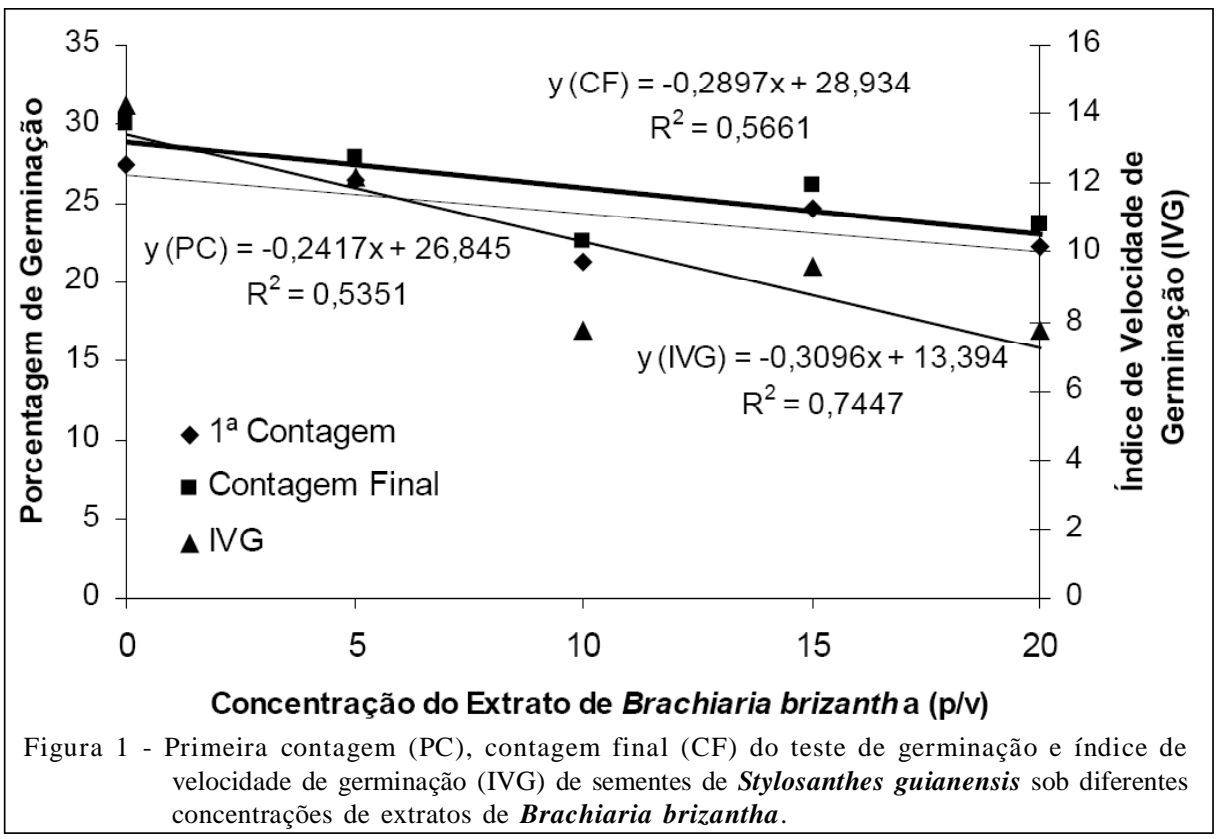

Ciência Rural, v.42, n.10, out, 2012. 


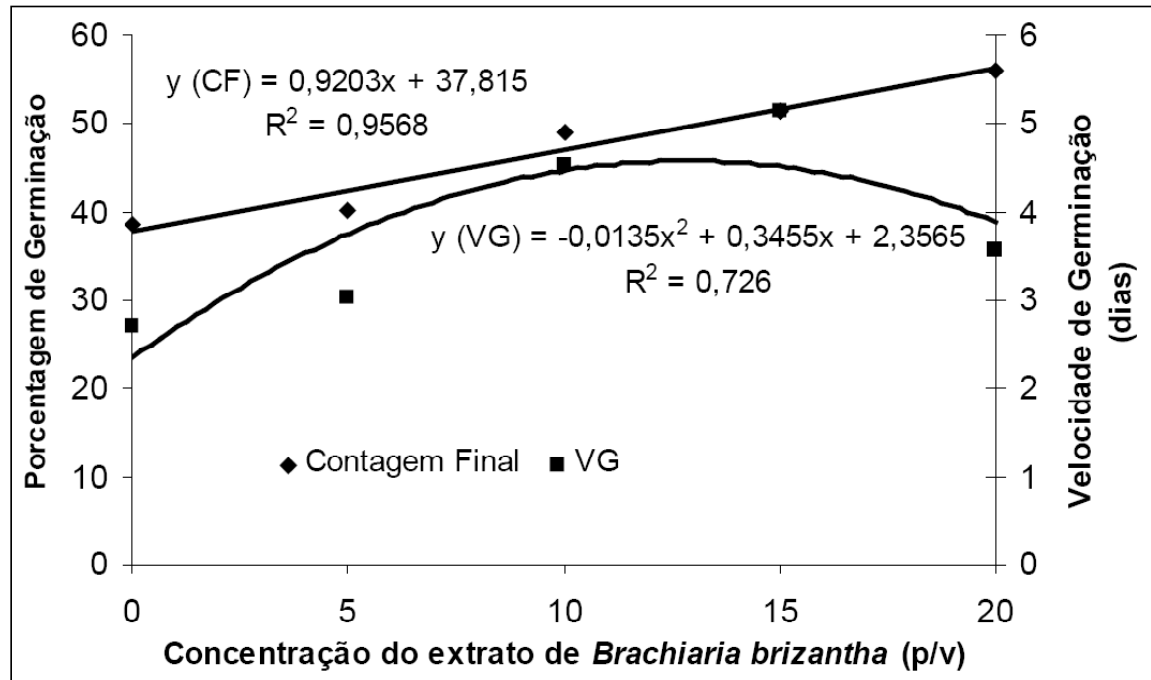

Figura 2 - Contagem final (CF) do teste de germinação e velocidade de germinação de sementes (VG) de Stylosanthes macrocephala sob diferentes concentrações de extratos de Brachiaria brizantha.

Outros estudos também avaliaram as interações alelopáticas entre espécies de Brachiaria e Stylosanthes e Brachiaria e outras leguminosas. STANIZIO et al. (1991) avaliaram o efeito alelopático de $\boldsymbol{B}$. brizantha cv. 'Marandu' na germinação e no crescimento de plântulas de $\boldsymbol{S}$. guianensis var. pauciflora cv. 'Bandeirante', S. guianensis var. vulgaris cv. 'Mineirão' e S. macrocephala cv. 'Pioneiro'. Foram utilizados extratos nas concentrações de $0,25,50$ e $100 \%$. Os autores observaram que os extratos não afetaram a germinação das sementes das leguminosas, mas prejudicaram os comprimentos da radícula e do hipocótilo das cvs. 'Bandeirante' e da var. vulgaris cv. 'Mineirão' e o comprimento da radícula da cv. 'Pioneiro'. Os extratos, nas concentrações de 50 e $100 \%$, diminuíram o crescimento da cv. Bandeirante, enquanto nas demais leguminosas foram reduzidas apenas pela concentração de $100 \%$. Os autores concluíram que a B. brizantha cv. 'Marandu' possui substâncias alelopáticas capazes de inibir o crescimento das leguminosas testadas, dependendo da concentração do extrato e das espécies testadas. Os resultados desse

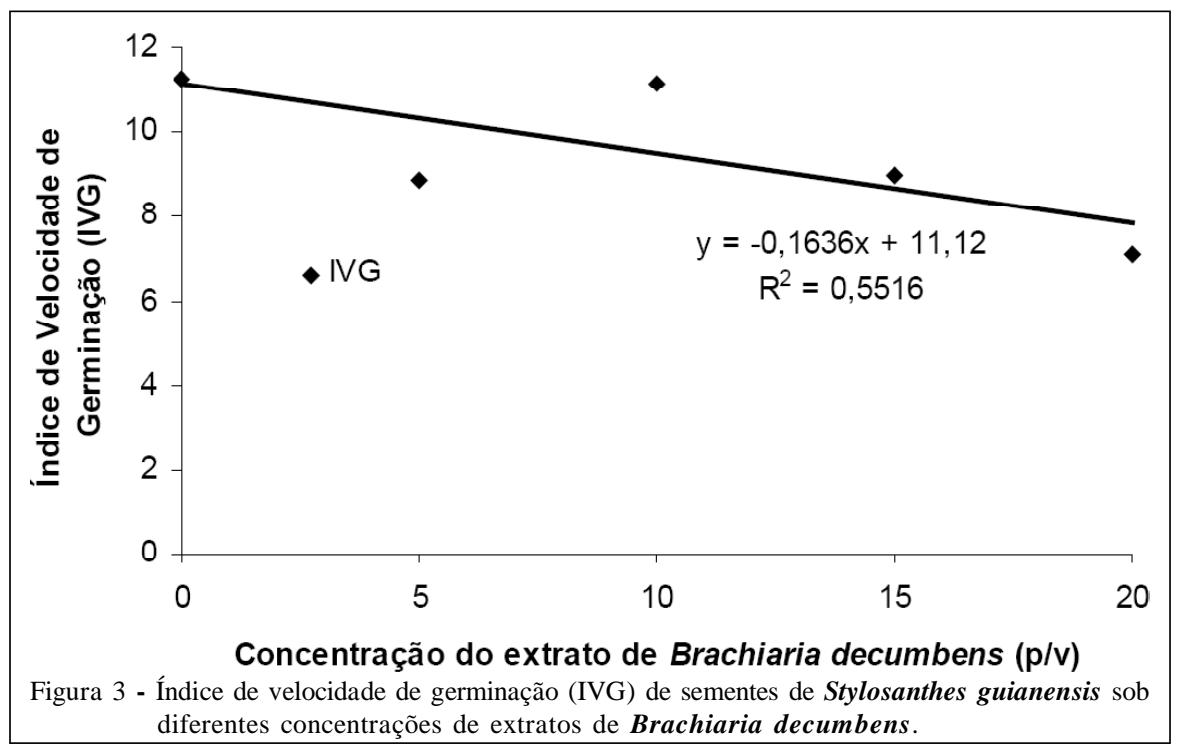

Ciência Rural, v.42, n.10, out, 2012. 


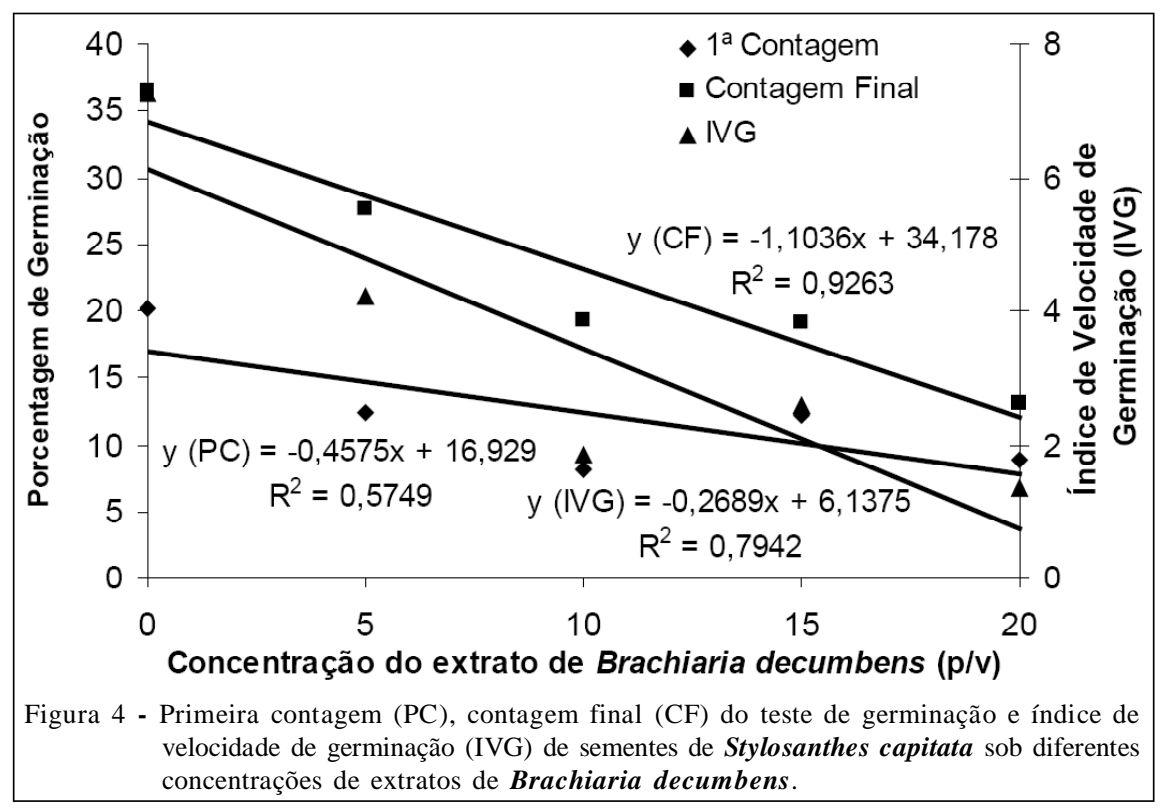

experimento, diferentemente dos de STANIZIO et al. (1991), mostram que os extratos de Brachiaria podem também influenciar na germinação de sementes de algumas espécies de Stylosanthes.

CARVALHO (1993) concluiu em seu trabalho que B. brizantha cv. 'Marandu' propiciou efeitos benéficos na velocidade de emergência das plântulas de Stylosanthes. No presente trabalho, B. brizantha também influenciou positivamente na porcentagem de germinação e parcialmente na velocidade de germinação de S. macrocephala, embora tenha agido negativamente na germinação de $S$. guianensis.

ALMEIDA (1997) avaliou, em laboratório, os efeitos alelopáticos de extratos aquosos de $\boldsymbol{B}$. decumbens, B. humidicola e B. brizantha cv. 'Marandu' na germinação e no desenvolvimento das leguminosas forrageiras Centrosema pubescens, Calopogonium mucunoides, Macrotyloma axillare cv. 'Guatá' e S. guianensis. Para S. guianensis, o autor encontrou que os extratos aquosos das braquiárias diminuíram a germinação das sementes da espécie. Os resultados do presente estudo corroboram parcialmente os encontrados por ALMEIDA (1993), pois, enquanto B. brizantha também influenciou negativamente na porcentagem de germinação da espécie de leguminosa, B. decumbens não apresentou efeito significativo negativo na porcentagem de germinação.

Conhecer os efeitos da alelopatia e suas interações inter e intra-específicas são de grande importância no contexto de qualquer ecossistema. Segundo REZENDE et al. (2003), tais informações possibilitam ao pesquisador identificar possíveis causas do insucesso no estabelecimento e persistência das pastagens, principalmente as consorciadas, propiciando a adoção de práticas de manejo que auxiliem na seleção de espécies promissoras, de forma a evitar prejuízos que possam ocorrer, decorrentes desses efeitos. Portanto, quanto mais estudos forem conduzidos no intuito de elucidar os efeitos alelopáticos e suas interações, mais próximo se estará da obtenção de pastagens puras ou consorciadas equilibradas, produtivas e auto-sustentáveis.

\section{CONCLUSÃO}

Há efeito alelopático negativo de Brachiaria brizantha e B. decumbens nas sementes de Stylosanthes guianensis e somente de B. decumbens em sementes de $\boldsymbol{S}$. capitata. Há efeito alelopático positivo de $\boldsymbol{B}$. brizantha nas sementes de $\boldsymbol{S}$. macrocephala. Não há efeito alelopático de $\boldsymbol{B}$. brizantha nas sementes de $\boldsymbol{S}$. capitata e nem de $\boldsymbol{B}$. decumbens em S. macrocephala.

\section{REFERÊNCIAS}

ALMEIDA, A.R.P.; et al. Efeitos alelopático de espécies de Brachiaria Griseb. sobre algumas leguminosas forrageiras tropicais. II. Avaliações em casa de vegetação. Boletim de Indústria Animal, v.54, p.45-54, 1997.

BRASIL. Ministério da Agricultura, Pecuária e Abastecimento. Regras para análise de sementes. Brasília : MAPA/ACS, 2009. 399p. 
CARVALHO, S.I.C. et al. Caracterização dos efeitos alelopáticos de Brachiaria brizantha cv. 'Marandu' no estabelecimento das plantas de Stylosanthes guianensis var. vulgaris cv. 'Bandeirantes'. Revista Brasileira de Zootecnia, v.22, p.930-937, 1993. Disponível em: <http:// www.revista.sbz.org.br/artigo/visualizar.php?artigo $=623>$. Acesso em: 11 ago. 2009.

CARVALHO, G.G.P; PIRES, A.J.V. Leguminosas tropicais herbáceas em associação com pastagens. Archivos de Zootecnia, v.57, p.103-113. 2008. Disponível em: <http:// www.uco.es/organiza/servicios/publica/az/php/img/web/ 25_12_52_894UsoCarvalho.pdf>. Acesso em: 11 ago. 2009.

GORLA, C.M.; PEREZ, S.C.J.G.A. Influência de extratos aquosos de folhas de Miconia albicans Triana, Lantana camara L., Leucaena leucocephala (Lam) de Wit e Drimys winteri Forst, na germinação e crescimento inicial de sementes de tomate e pepino. Revista Brasileira de Sementes, v.19, n.2, p.260265, 1997. Disponível em: <http://www.abrates.org.br/revista/ artigos/1997/v19n2/artigo19.pdf>. Acesso em: 11 ago. 2009.

GRESSEL, J.B.; HOLM, L.G. Chemical inhibibition of crop germination by weed seed and the nature of the inhibition by Abutilon theophrasti. Weed Research, v.4, p.44-53, 1964.

MACIEL, C.D.G. et al. Influência do manejo da palhada e capim-braquiária (Brachiaria decumbens) sobre o desenvolvimento inicial de soja (Glycine max) e amendoimbravo (Euphorbia heterophylla). Planta Daninha, v.21, n.3, p.365-373, 2003. Disponível em: <http://www.scielo.br/pdf/ pd/v21n3/a03v21n3.pdf $>$. Acesso em: 11 ago. 2009.

REZENDE, C.P. et al. Alelopatia e suas interações na formação de pastagens. Informe Agropecuário, n.54. p.1-55, 2003. Disponível em: <http://www.editora.ufla.br/BolTecnico/pdf/ bol_54.pdf>. Acesso em: 11 ago. 2009.
RICE, E.L. Allelopathy. 2.ed. New York: Academic, 1984. $422 \mathrm{p}$.

SILVA, J.J.; SALIBA, E.O.S. Pastagens consorciadas: uma alternativa para sistemas extensivos e orgânicos. Veterinária e Zootecnia, v.14, p.8-18, 2007. Disponível em: <http:// ww w.fmvz.unesp.br/revista/volumes/vol1 4/ Revista\%20v14n01_2007_8_18.pdf>. Acesso em: 11 ago. 2009.

SILVA, S.C.; SBRISSA, A.F. A planta forrageira no sistema de produção. In: SIMPÓSIO SOBRE MANEJO DA PASTAGEM, 17., 2000, Jaboticabal, SP. Anais... Jaboticabal: FEALQ, 2000. p. 3-20.

SOUZA FILHO, A.P.S. et al. Potencial alelopático de forrageiras tropicais: efeitos sobre invasoras de pastagens.

Planta

Daninha, v.15, n.1, p.53-60, 1997.

STANIZIO, R.M. et al. Efeito alelopático de Brachiaria brizantha cv. 'Marandu' sobre o crescimento de plantas de quatro leguminosas forrageiras. In: REUNIÃO ANUAL DA SOCIEDADE BRASILEIRA DE ZOOTECNIA, 28., 1991, João Pessoa, PB. Anais... João Pessoa: SBZ, 1991. p.95.

SOUZA FILHO, A.P.S. et al. Aleloquímico produzido pela gramínea forrageira Brachiaria humidicola. Planta Daninha, v.23, n.1, p.25-32, 2005. Disponível em: <http://www.scielo.br/ pdf/pd/v23n1/23925.pdf>. Acesso em: 11 ago. 2009.

SOUZA, L.S. et al. Efeito alelopático de capim-braquiária (Brachiaria decumbens) sobre o crescimento inicial de sete espécies de plantas cultivadas. Planta Daninha, v.24, n.4, p.657-668, 2006. Disponível em: <http://www.scielo.br/pdf/ pd/v24n4/a06v24n4.pdf>. Acesso em: 11 ago. 2009. 